Supplement of Atmos. Chem. Phys., 20, 7259-7269, 2020

https://doi.org/10.5194/acp-20-7259-2020-supplement

(C) Author(s) 2020. This work is distributed under

the Creative Commons Attribution 4.0 License.

(c) (i)

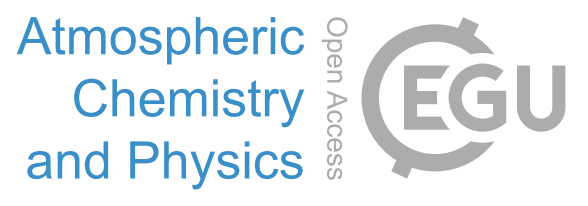

Supplement of

\title{
Importance of gas-particle partitioning of ammonia in haze formation in the rural agricultural environment
}

\section{Jian Xu et al.}

Correspondence to: Kan Huang (huangkan@ fudan.edu.cn)

The copyright of individual parts of the supplement might differ from the CC BY 4.0 License. 


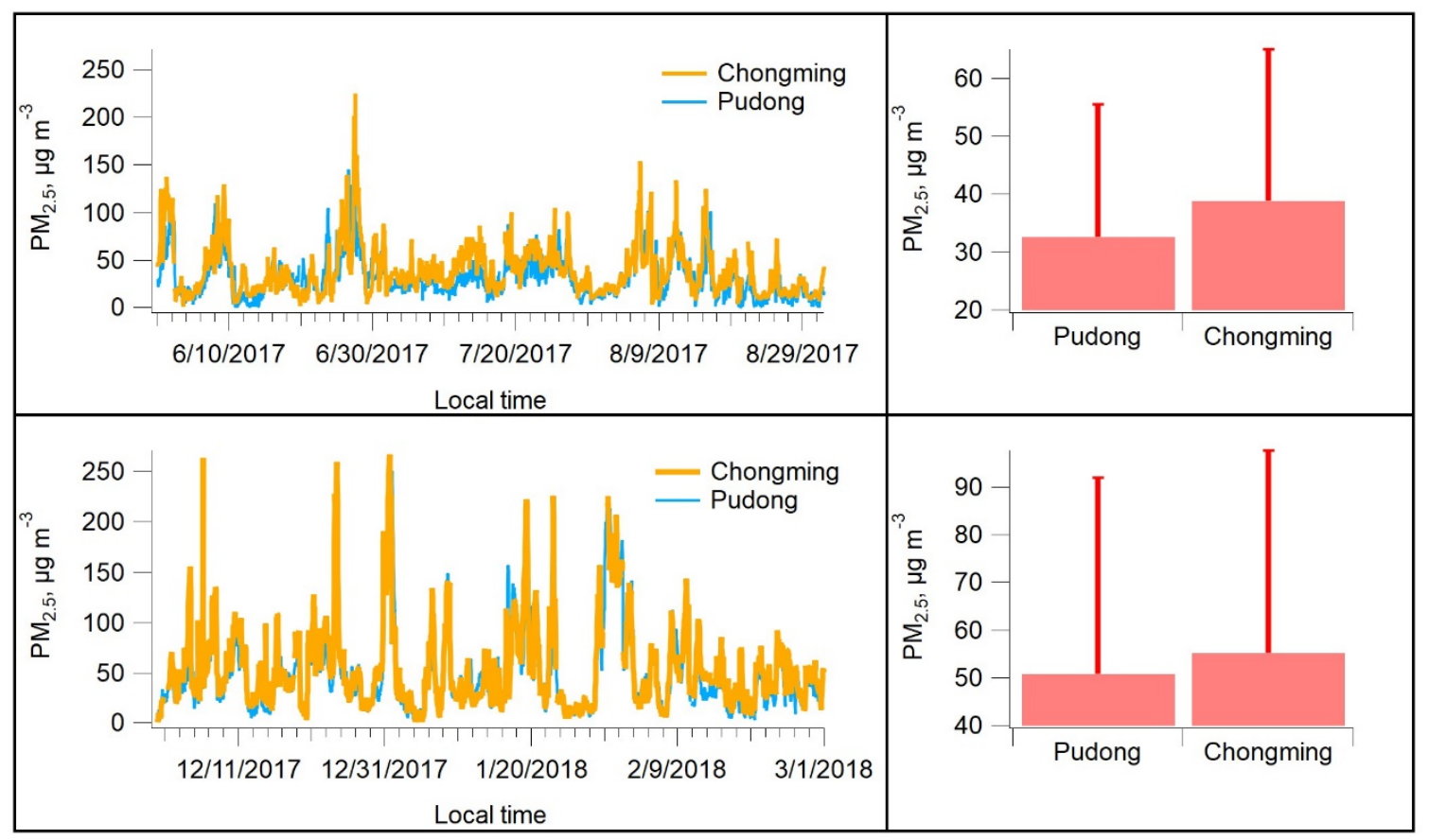

Figure S1: $\mathrm{PM}_{2.5}$ at Chongming (rural) and Pudong (urban) in summer (top) and winter (bottom). 

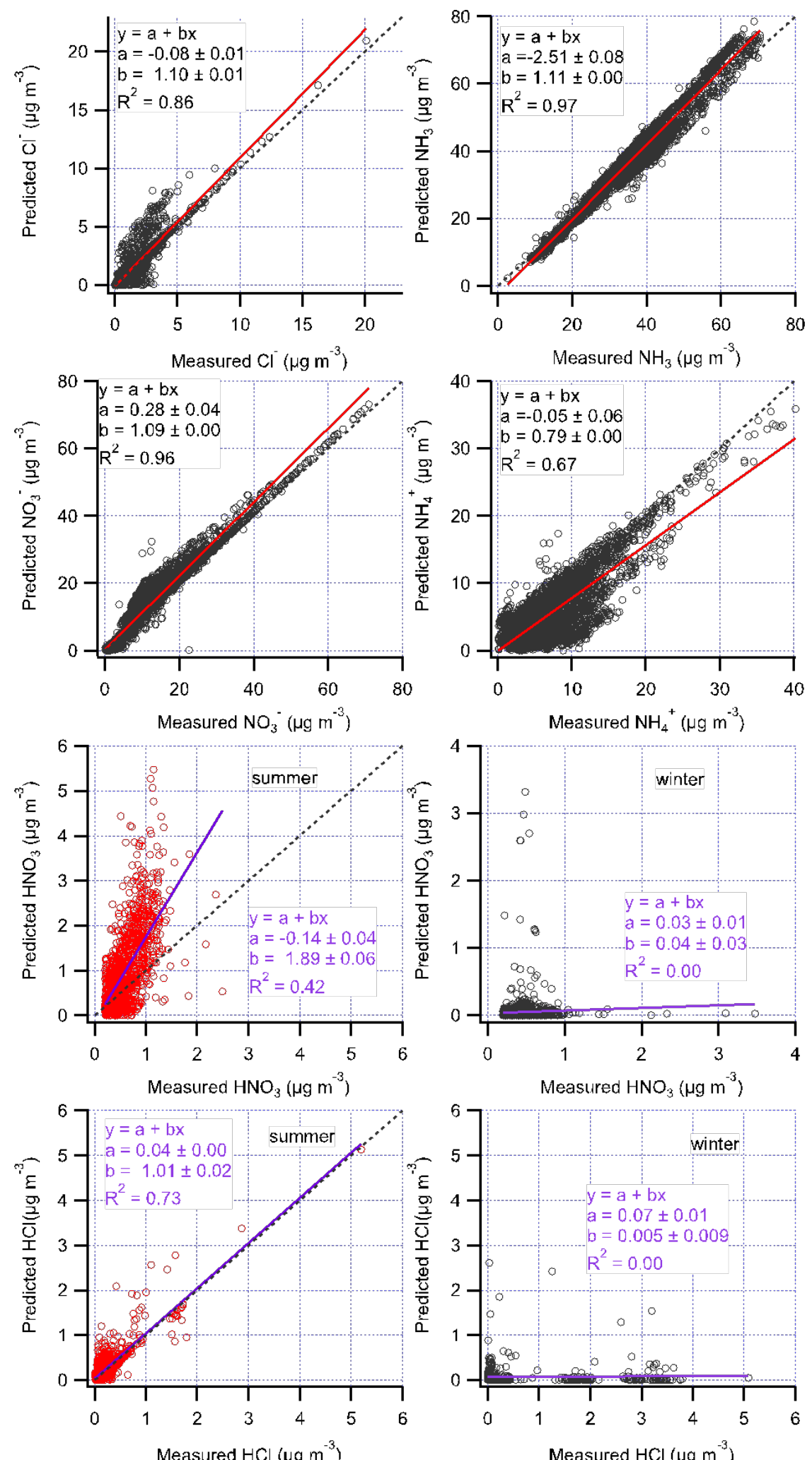

Figure S2: Comparison of predicted and measured $\mathrm{Cl}^{-}, \mathrm{NO}_{3}{ }^{-}, \mathrm{NH}_{3}, \mathrm{NH}_{4}{ }^{+}$, and $\mathrm{HNO}_{3}$ and $\mathrm{HCl}$ in summer and in winter, respectively. Orthogonal distance regression (ODR) fits with $\pm 1 \sigma$ are shown. 
Table S1: District level emission (unit: $\mathrm{Mg}$ /year) of $\mathrm{NH}_{3}, \mathrm{SO}_{2}$, and $\mathrm{NO}_{x}$ in Shanghai based on the MEIC emission inventory (MEIC, www.meicmodel.org)

\begin{tabular}{ccccccc}
\hline Name & $\begin{array}{c}\text { Agriculture } \\
\mathbf{N H}_{\mathbf{3}}\end{array}$ & $\begin{array}{c}\text { Agriculture } \\
\text { NO }_{x}\end{array}$ & $\begin{array}{c}\text { Agriculture } \\
\mathbf{S O}_{2}\end{array}$ & $\begin{array}{c}\text { All } \\
\text { NH }_{3}\end{array}$ & $\begin{array}{c}\text { All } \\
\text { NO }_{x}\end{array}$ & All_SO $_{2}$ \\
& 371.7 & 0 & 0 & 679.7 & 33924.2 & 15352.2 \\
\hline Baoshan & 59.4 & 0 & 0 & 113.4 & 4850.9 & 2298.9 \\
Changning & $\mathbf{3 0 5 7 . 5}$ & $\mathbf{0}$ & $\mathbf{0}$ & $\mathbf{3 2 4 2 . 6}$ & $\mathbf{1 8 5 4 3}$ & $\mathbf{7 6 9 9}$ \\
Chongming & 2620.7 & 0 & 0 & 2747.9 & 11981.3 & 5646.3 \\
Fengxian & 28.5 & 0 & 0 & 51.9 & 2579.7 & 1176.4 \\
Hongkou & 35.3 & 0 & 0 & 64.5 & 2629 & 1247.5 \\
Huangpu & 1183.5 & 0 & 0 & 1616.3 & 36659.2 & 15866.7 \\
Jiading & 2343.8 & 0 & 0 & 2460.4 & 11107.4 & 5107.1 \\
Jinshan & 47.7 & 0 & 0 & 89.7 & 4282 & 1960.2 \\
Jingan & 83.1 & 0 & 0 & 149.5 & 6590.2 & 3025.4 \\
Putuo & 4184.5 & 0 & 0 & 4770.5 & 66681.2 & 33267.8 \\
Pudong & 1578.5 & 0 & 0 & 1802.9 & 17867 & 8333.1 \\
Qingpu & 1810.4 & 0 & 0 & 2130.5 & 28012.5 & 13287.7 \\
Songjiang & 88.1 & 0 & 0 & 168.1 & 7193 & 3408.9 \\
Xuhui & 77.3 & 0 & 0 & 117.8 & 6134.7 & 3091.3 \\
Yangpu & 851.6 & 0 & 0 & 1317.2 & 42765.9 & 20401 \\
Minhang & 18421.6 & 0 & 0 & 21522.9 & 301801.2 & 141169.5 \\
Total & & & & & & \\
\hline
\end{tabular}

